
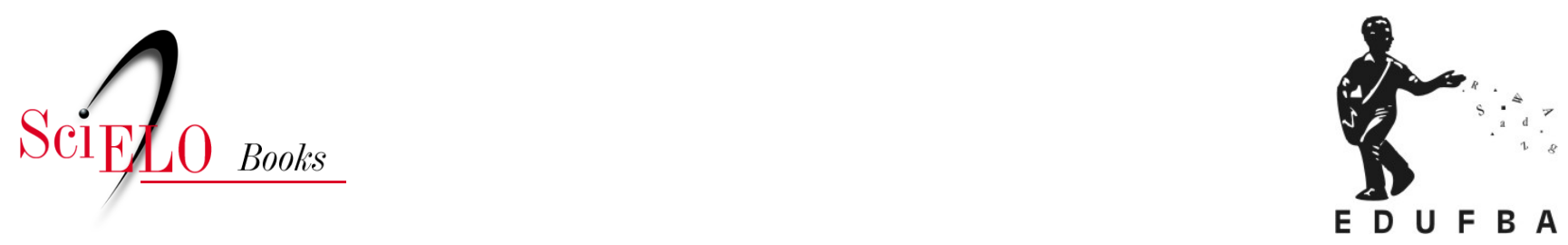

\title{
Blanqueamiento social, nación y moralidad en América Latina
}

\author{
Mara Viveros Vigoya
}

\section{SciELO Books / SciELO Livros / SciELO Libros}

VIGOYA, M.V. Blanqueamiento social, nación y moralidad en América Latina. In: MESSEDER, S., CASTRO, M.G., and MOUTINHO, L., orgs. Enlaçando sexualidades: uma tessitura interdisciplinar no reino das sexualidades e das relações de gênero [online]. Salvador: EDUFBA, 2016, pp. 17-39. ISBN: 978-85-232-1866-9. https://doi.org/10.7476/9788523218669.0002.

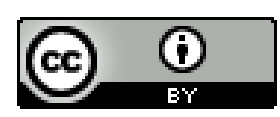

All the contents of this work, except where otherwise noted, is licensed under a Creative Commons Attribution $\underline{4.0 \text { International license. }}$

Todo o conteúdo deste trabalho, exceto quando houver ressalva, é publicado sob a licença Creative Commons Atribição 4.0. 


\title{
Blanqueamiento social, nación y moralidad en América Latina ${ }^{\mathrm{I}}$
}

\author{
灌 \\ Mara Viveros Vigoya
}

\section{Introducción}

En esta ponencia voy a rastrear cómo han interactuado el blanqueamiento social y la moralidad, en América latina mostrando las continuidades y discontinuidades que han tenido estas percepciones desde el período colonial y en relación con la constitución progresiva del significado contemporáneo del término raza para clasificar a las poblaciones según criterios que entrelazan

\footnotetext{
${ }^{1}$ Por se tratar de texto em língua estrangeira, preservaremos a estrutura textual e normas técnicas do país de origem, sendo de total responsabilidade da autora a forma apresentada e adotada.
} 
características fenotípicas y cualidades morales que pueden ser transmitidas de generación en generación (Hering 2007, Leal León 2010). Como sugiere la presentación del Seminario voy a dar cuenta de reglas, normas, pausas, y tensiones que operan en esta relación y en sus efectos tanto para las interacciones cara a cara, como para las relaciones institucionales.

Antes de dar cuenta de la historicidad del proceso de este proceso desde el periodo colonial voy a hacer dos precisiones. La primera, se refiere al uso que hago de la categoría América Latina. Si bien es claro que hay muchas diferencias entre los países que componen esta región e incluso hay muchas variaciones internas al interior de un mismo país, para el propósito de esta conferencia me parece pertinente subrayar algunos puntos comunes que comparten estos países: uno de ellos es el lugar que ocupa el mestizaje en sus historias como un proceso que ha sido culturalmente estructurante y como una ideología política nacionalista. Otro, es la estrecha relación que tienen la raza, la etnicidad, la clase, el género y la sexualidad en las dinámicas sociales de la región y la forma en que las identidades sociales marcan, matizan o reinterpretan las diferencias culturales, sociales o biológicas heredadas.

La segunda precisión es explicar que entiendo por blanqueamiento la búsqueda de escapar de lo "negro" para asegurarse una mejor forma de existencia social en un contexto que valora lo "blanco" como sinónimo de progreso, civilización y belleza. Esta búsqueda se lleva a cabo de dos modos, primero, a través del mestizaje en un proceso intergeneracional, y en segundo lugar, a través de la integración a redes sociales no negras. Mientras que el primero es evidente en la apariencia física, estoy más interesada en el segundo, porque revela la dinámica social en juego. En lo que llamo blanqueamiento social interactúan distintas fuerzas: ideológicas, sociales y personales. La dimensión ideológica del blanqueamiento social ha sido construida en relación con una identidad nacional que privilegia lo blanco, o lo que se acerca a él, y restringe el espacio social y simbólico que ocupan las poblaciones indígenas y afrodescendientes; la dimensión social alude a las dinámicas que actúan para "diluir y dispersar lo negro 
y la cultura negra" (Wade 1997: 350) y la dimensión personal incluye las diversas prácticas cotidianas que realizan los grupos e individuos sociales identificados como no blancos para adecuarse a los valores culturales, sociales y morales "blancos"

Hechas estas dos precisiones voy a referirme al blanqueamiento y a sus connotaciones morales desde una perspectiva que busca dar cuenta de la forma en que las categorizaciones sexuales y de género han sido históricamente configuradas en relación con las categorizaciones de raza”

\section{Orden Colonial: honor, sexualidad y religión}

En el contexto colonial latinoamericano, la certificación de limpieza de sangre - que operaba en la península ibérica y exigía documentar una ascendencia sin mácula religiosa de judíos o musulmanes - se transformó paulatinamente en la necesidad de probar no tener ancestros negros, mulatos, zambos, cuarterones, etc., visibles en el color de la piel y en ciertos rasgos fisionómicos (Hering 2007, 2010). Al mismo tiempo, la misma dinámica colonial que creó las castas permitió procesos de ascenso social por blanqueamiento, posibilitando a "indios" y "negros" sobrepasar los límites que su condición les imponía mediante un proceso de sucesivos mestizajes a través de varias generaciones (Leal León 20Io).

No hay que olvidar, sin embargo, que la blanquidad era también una cuestión de reputación, ya que una persona podía ser blanca si así era considerada públicamente (Wade 2009: 70). Las informaciones provenientes de distintos documentos oficiales permiten afirmar que "el color se convertía fácilmente en un instrumento de poder, aplicable ante la ley colonial para conseguir ciertos fines [...]. El color, igual que la memoria, era una categoría moldeable en la cotidianidad y que se definía según la situación.” (Hering 20I0: 144).

En una sociedad altamente estratificada como la de las colonias ibéricas, los blancos ocupaban la cúspide de la pirámide, los indios y los negros estaban en la base (si bien los indios gozaban de protección legal y los negros 
no), y el espacio social intermedio estaba dominado por una amplia variedad de no blancos legalmente libres. La escasez de mujeres blancas, la falta de control sobre amplias zonas del territorio y las medidas legales que permitían a los esclavos comprar su libertad propiciaron el surgimiento de una población mezclada racialmente y socialmente reconocida, que se convirtió en la mayoría en varias áreas del territorio a partir del siglo XVIII.

En la medida en que la categoría de personas mezclada creció numéricamente y en algunos casos consiguió riqueza y estatus social, el asunto del estatus racial cobró mayor importancia para la elite blanca. Así, la regulación del matrimonio y el parentesco, y de ciertos actos sexuales, a través de leyes y decretos, se convirtió en una cuestión clave para mantener estas jerarquías y preservar los privilegios político-económicos que conferían el honor y la pureza de sangre. En esta operación fue crucial el control del comportamiento sexual de las mujeres de la elite, consideradas como los agentes que podían traer contaminación al interior de la familia, amenazando la pureza de sangre que definía en buena parte la posición social de la elite en la jerarquía social y racial.

La castidad o "virtud de las mujeres" (esposas, hermanas, madres, hijas) se convirtió entonces en el significante del honor familiar. En concordancia, las mujeres blancas de la elite ocultaron o interrumpieron los embarazos fruto de uniones con hombres de menor rango social para preservar la continuidad del sistema que privilegiaba a los hombres blancos. Las mujeres no blancas o pobres quedaron mientras tanto expuestas a asaltos masculinos que muy fácilmente podían mancillar su honor y devaluar su estatus social. El honor como estatus social y el honor como virtud estaban tan inextricablemente unidos que las únicas que podían aspirar realmente al honor y al estatus social que le estaba asociado, mediante un comportamiento adecuado, eran las mujeres blancas de la elite.

La institución que permitió conectar la dominación sexual con la dominación racial, y al Estado con la familia para definir el estatus social fue el matrimonio. Ahora bien, a pesar de que se buscó dar prioridad al matrimonio entre iguales social y económicamente" esta regla tuvo su excepción, 
como lo muestra VerenaStolcke (1992) para el caso de la sociedad cubana decimonónica. Las parejas que deseaban casarse con alguien que fuera considerado por sus padres como socialmente desigual, recurrían al rapto de la mujer como una estrategia para legitimar la unión nacida de la deshonra a la que se había expuesto por tener una relación por fuera del matrimonio. No obstante, este tipo de acciones se prohibió por medio de una coerción mayor, ya que el riesgo que enfrentaba la Corona Española con el creciente número de mezclas formadas a través de estas uniones interraciales era alto.

Entretanto, las relaciones extramatrimoniales incluso interraciales no impugnaban la honorabilidad personal de los varones. Sin embargo, se intentó limitar estas prácticas, no tanto por razones morales sino porque podían desestabilizar la seguridad del estatus de la élite al ayudar a crear una clase mixta de la cual surgían individuos que aspiraban al honor y al estatus asociado y podían conseguirlo mediante peticiones a la Corona española la Palacio de Justicia en Brasil (Wade 2009: 96). Las políticas que impidieron el matrimonio interracial en el periodo colonial fueron siempre un tema de tensiones y controversias, cuyo trasfondo era la búsqueda de continuidad de un orden social basad en jerarquías de raza y sexo. No hay que olvidar que en América Latina y particularmente en el Caribe todavía subsistía el pánico suscitado por la revolución haitiana (I79I-I804) que constituyó la primera república negra independiente convirtiendo a la isla en un escenario peligroso para la corona española.

Aunque el honor fue un valor ampliamente aceptado en el periodo colonial, la gente del común parece haber intentado resistido a su mandato desarrollando una perspectiva distintiva en relación con la moral. Por ejemplo, las uniones consensuales fueron muy frecuentes entre las capas plebeyas de las ciudades coloniales de México, Lima y Santa Fe y parecen haber sido aceptadas como una norma cultural de ese grupo. Igualmente, tener hijos fuera del matrimonio no impedía necesariamente a una mujer del común poder realizar más tarde un matrimonio y la castidad femenina tenía un valor menor que en la elite (Cope i994: 69 citado por Wade 
2009). Sin embargo el matrimonio fue una institución ampliamente valorada por toda la población y era una meta a la que se aspiraba

Los códigos de honor tuvieron diferentes perspectivas para mujeres y hombres: para éstos, el honor podía depender en gran medida del poder de su autoridad y no se afectaba por relaciones sexuales o arreglos familiares y parentales con mujeres de clases sociales y grupos étnico raciales percibidos como inferiores, mientras que para las mujeres, podía depender más o provenir directamente de su familia. Por esta misma razón, las maneras de resistir a sus mandatos también estuvieron bastante orientadas por su posición de género. Las mujeres de las castas intentaron acceden al honor, así fuera parcial, para ellas o para sus hijos retando las jerarquías raciales a través de uniones interraciales. $Y$ en otros casos, se ampararon en los valores coloniales del honor y del respeto merecido para justificar su participación en actos insurgentes (Stern 1995:302-8).

Un ejemplo interesante de resistencia femenina indígena frente a la colonización ibérica es el descrito por Irene Silverblatt (1987) en su libro sobre las ideologías de género y clase en el imperio Inca y el Perú coloniales: Silverblatt se refiere al caso de las acllas o vírgenes andinas, mujeres de singular belleza, destinadas al culto religioso y en algunos casos asignadas como esposas para el emperador u otros hombres de importancia. Estas mujeres tenían a su cargo la preparación de comidas protocolares y la costura y el tejido de ciertos elementos rituales. En las nuevas condiciones que impuso la colonización su virginidad cobró un nuevo significado, convirtiéndose en una medida de protección que las llevó a aislarse en la Puna (meseta) para desaparecer tanto de los ojos de los conquistadores para evitar su lujuria, como de la vigilancia de las autoridades coloniales.

Pese a los intentos de los sectores subalternos de resistir a la imposición de valores sexuales y morales por parte de los españoles no era muy fácil articular exigencias de derechos y defensas contra los abusos por fuera del contexto axiológico y religioso dominante (Villegas del Castillo Historia Critica, 2006). Así, las demandas que las y los plebeyos hicieron 
ante las autoridades judiciales solicitando su intervención en los conflictos familiares invocaron el mismo ideario cultural de las elites

En su libro Race and Sex in Latin America Wade reporta como ejemplo de resistencias a las normas morales dominantes el de las "comunidades de sodomitas 'establecidas en las ciudades coloniales y estudiadas por Luiz Mott en Brasil. Si bien este trabajo ha sido criticado como esencialista, por plantear la existencia de una subcultura gay embrionaria en Brasil, por utilizar en forma anacrónica el termino gay, propio del siglo XX, no es improbable que hayan existido redes más o menos organizadas, gestadas en las iglesias, los campos de cultivo o las playas, cuyo objetivo era asegurar la posibilidad de mantener prácticas sexuales disidentes.

En el intento de preservar el orden social, sexual, racial y moral de esta nueva sociedad, orientada por los principios ibéricos pero adecuados a las condiciones locales, las autoridades coloniales echaron mano de otra institución, la de la Inquisición. Los colonizadores españoles y portugueses vincularon la inmoralidad sexual al paganismo y persiguieron la brujería, no únicamente como herejía sino también como un ámbito muy sexualizado. Gran parte del contenido del Malleus Maleficarum, el manual utilizado por los tribunales de la Inquisición establecidos en México y Lima en I569 y posteriormente en Cartagena de Indias en i6ıo, hacía referencia a asuntos relacionados en mayor o menor medida con la sexualidad.

Si bien muchas de las ofensas buscadas se clasificaban como blasfemia y herejía, trabajos como el de Luiz Mott en Brasil señalan que muchos de los sacrilegios investigados por la inquisición en Brasil tenían contenidos sexuales. Mientras las prácticas homoeróticas masculinas fueron susceptible de persecución, las prácticas "nefandas" de las mujeres fueron rara vez causa de preocupación. Según la investigación bibliográfica realizada por Wade, la distinción actividad/pasividad sexual fue claramente utilizada para reforzar las ideas de dominación de género; sin embargo, los pocos datos existentes sobre el aspecto racial de las prácticas homosexuales no autorizan afirmar o negar que las prácticas homoeróticas reforzaron o socavaron las jerarquía raciales. 
Aunque todos los residentes de la colonia eran susceptibles de ser denunciados ante la inquisición, es evidente, como lo muestra Jaime Borja para Colombia que la sexualidad de las poblaciones negras, indígenas y mestizas fue sometida a un más estricto escrutinio. De este modo, concubinato, adulterio y sodomía fueron pecados asociados muy frecuentes con las poblaciones racializadas y la brujería se asimiló con la prostitución y los comportamientos sexualmente licenciosos (Wade: 2009: 85). Las instituciones que perseguían a las brujas y a la heterodoxia religiosa imponían simultáneamente un orden moral-sexual y racial: así, aquellos considerados indios, negros y mestizos fueron percibidos muy frecuentemente como sexual y religiosamente heterodoxos. En Brasil, por ejemplo, el término mandingueiro, derivado de la etnia Mandinka de África del Oeste, se convirtió en sinónimo de hechicero. En los Andes, las campañas religiosas que buscaron extirpar la idolatría se focalizaron sobre las poblaciones indígenas, y particularmente sobre las mujeres que no solo fueron tildadas de paganas sino de sexualmente inmorales. Sin embargo, aún con la amenaza de la inquisición en este periodo también se generaron espacios de libertad y autonomía sexual y ni este ni ningún otro sistema de represión fue capaz de llegar a cada individuo y grupo social.

En resumen, en el periodo colonial los dispositivos de pureza de sangre que hacían referencia inicialmente únicamente a la religión se convirtieron en mecanismos de dominación racial que operaron a través de normas patriarcales para producir una descendencia legítima, salvaguardar los privilegios materiales y simbólicos de las élites y garantizar la continuidad de este orden colonial (Wade 2009: 9I).

\section{Las normas sociales de sexo y género en el surgimiento de las nuevas republicas}

A partir del inicio del siglo ig, la disolución del Imperio Español en América (como fruto de las luchas por la Independencia) planteó el problema del nuevo orden social. Libradas a su suerte, las excolonias ibéricas del norte y del sur de América enfrentaron la necesidad de garantizar y normalizar un 
nuevo equilibrio y unas nuevas formas de autoridad política. Igualmente, debieron lidiar de distintas formas con el dilema planteado por la composición racial de sus poblaciones -visiblemente mezcladas- en relación con el deseo y la voluntad de acceder a las ventajas del progreso y la civilización propios de las naciones modernas. La disyuntiva que trazaba la composición racial de las poblaciones exigió crear un espacio político importante para los problemas de la raza, categoría que ocupó un lugar relevante en el pensamiento científico occidental de la época y fue el concepto que permitió articular la modernidad con la blanquitud (Wade 2009: II4).

Sin embargo, la lógica de clasificación racial que diferenciaba grupos considerados provistos o desprovistos de determinados atributos por naturaleza, entraba en contradicción con el nuevo modelo de ciudadanía que pretendía fundar la legitimidad del poder político republicano. Por ello, una vez eliminadas las diferencias legales, las categorías raciales se volvieron más fluidas y el mestizaje empezó a ser valorado como característica de las nuevas naciones. El mestizaje, como una forma de blanqueamiento progresivo, se convirtió en una promesa de inclusión en la comunidad de ciudadanos² no solo a través de los casamientos con personas "más blancas" sino por adecuación a los valores de respetabilidad y honor considerados propios de los grupos construidos como blancos. De este modo, el mestizaje pudo ser una fuente de estatus que podía reivindicarse ya sea como atributo natural o como resultado de un proyecto personal, no solo aceptado sino deseado (Moreno Figueroa, 20I2).

A la preocupación decimonónica por la consolidación de un Estado nación, se sumó un proyecto de modernización nacional en el cual jugaron un papel relevante políticos y médicos. Convencidos de que el progreso de un país requería de la participación de todos los nacionales, y basados en un discurso biológico que le atribuía ciertas características "raciales" a las distintas poblaciones, médicos y políticos emprendieron

\footnotetext{
2 El uso del masculino para ciudadanos da cuenta de las restricciones que tenía el ejercicio de ciudadanía para las mujeres (Leal León 2010: 395); no sobra recordar que el derecho al voto femenino solo se logró en la segunda mitad del siglo XX, en 1957.
} 
campanas reformistas con el fin de mejorar la "raza colombiana”. Las ideas de vigor y salud en la regulación de la sexualidad fueron interpretadas en un marco nacional y el bienestar y la fortaleza reproductiva de la población constituyeron un nuevo horizonte político de los gobernantes. Los grupos racializados, que se ubicaban en la base de la pirámide social (permitiendo amalgamar clase social y raza), fueron convertidos en objetivos primordiales de la acción higienista y civilizadora de las élites blancas.

Así, la encrucijada que planteaba la composición racial de las poblaciones de las nuevas naciones necesitó la puesta en marcha de políticas higienistas, programas eugenésicos, medidas de renovación urbana y planes para incrementar el acceso a la educación y la extensión, a todos los grupos sociales, de los valores ligados a la modernidad. El higienismo operó, como lo recuerda Ángela Facundo (200) a partir de su análisis del caso colombiano, en los dos ámbitos establecidos para desarrollar el ideal del progreso: el ámbito remedial y el de formación. Lo remedial estuvo claramente encaminado a detener y revertir lo que muchos médicos consideraron una degeneración progresiva de la raza y lo formativo se orientó principalmente hacia la niñez con el objetivo de modificar los hábitos y costumbres desde la temprana infancia y hacia las madres, encargadas de velar por el cumplimiento de los preceptos modernos sobre el nacimiento, la crianza, la educación y el comportamiento en general.

La familia fue el foco de las estrategias remediales y formativas emprendidas para la reforma del pueblo colombiano y la mujer fue considerada como "la responsable de reformar a los hijos de la patria en aras de consolidar una nueva nación fuerte y vigorosa”. Por esta razón, una vez realizada la tarea de educación de las madres sobre el cuidado de los hijos, quedaba pendiente la tarea de formar el espíritu de las mujeres en la honradez y la virtud. Para ellas se delimitaron no sólo sus funciones como madres, sino también la edad ideal para casarse, iniciar la vida sexual, tener hijos y realizar cada tarea en función de su etapa de vida. Los tratados de economía doméstica y los manuales de buenas maneras buscaron extender el alcance de los programas higienistas y orientar a las mujeres a cumplir 
con sus obligaciones sin incurrir en vicios y costumbres que dificultaran el progreso nacional. La economía doméstica debía estar en consonancia con las prédicas del ahorro y la racionalidad de los recursos impuestas con el proyecto modernizador, de modo tal que una buena administradora del hogar, haría de este lugar un nicho acogedor para su esposo, alejándolo de los vicios del juego, el alcohol y la prostitución, para convertirse en padre y marido ejemplar, en un trabajador incansable y en un miembro productivo de la sociedad.

Estos textos, empleados desde finales del siglo XIX, se difundieron ampliamente como parte del dispositivo higienista. Vale la pena citar uno de ellos, referido por Ángela Facundo, para dar cuenta del carácter controlador de sus instrucciones y de las representaciones en boga sobre las mujeres y a feminidad:

La mujer que se levanta al aclarar el día puede emplear sin afán las dos primeras horas en el arreglo de su cama, cuarto, tocador y aún la casa toda; otra hora en el aseo y adorno personal y media hora en su desayuno; y ya desembarazada de estos quehaceres, tiene delante de sí más de ocho horas de cuyo buen uso podrá sacar grande utilidad. Sea cual fuere su oficio, o profesión, le será ventajosísimo no emprenderle hasta que haya puesto orden en su casa, y que su persona esté con el aseo y la compostura que permitan las circunstancias (Acevedo, I848:6).

Las mujeres fueron vistas y representadas por el discurso médico no sólo como madres biológicas sino también como madres morales de los hijos, la familia, la sociedad y la nación. El caso argentino estudiado por Donna Guy muestra los cambios en los conceptos de maternidad que trajo la participación e intervención médica en estados nación que alcanzaron la modernidad a finales del siglo ig. La salud pública nacional argentina como tal solo se organiza después de que se resuelven los problemas sanitarios urgentes, ligados a la llegada de continuas olas de inmigrantes europeos. En el contexto de las campañas de Salud que se emprendieron 
a comienzos del siglo XX para disminuir la mortalidad infantil, la madre moderna empezó a ser evaluada no solo por el número de hijos que podía dar a luz sino por su buena crianza. Un dato interesante del estudio de Guy es su referencia a la participación de las mujeres feministas en la definición de la maternidad, aceptada como un destino que debían cumplirlas mujeres modernas, mientras planteaban la necesidad de que las madres gozaran de independencia social y económica. De hecho, en el primer congreso femenino Internacional realizado en Buenos Aires en I9Io se expidió una declaración en la cual se invocaba que las madres, así fueran solteras o casadas merecían asistencia social. Escritoras feministas como Raquel Camaña vincularon la maternidad con la democracia y plantearon la centralidad que debía ocupar el proyecto de una democracia vital, anclado en la familia y aún más importante para la sociedad que el de la democracia política o industrial (Guy I99I).Los problemas planteados por la asistencia y la educación de niños abandonados que trajo la vida urbana requerían una imagen materna no solo afectuosa sino higiénica que incorporara elementos del conocimiento médico y psicológico de la época con miras a obtener un ejercicio adecuado de la maternidad. Por ello, la Sociedad de Beneficencia creó en I92I una escuela para enseñar a las madres como cuidar a sus hijos de acuerdo con los conceptos de la puericultura. Como dice Donna Guy, en la visión republicana de la maternidad las madres empezaron a ser importantes no solo por su vientre y su seno sino por sus conocimientos, su compromiso emocional y la conciencia de su deber patriótico.

$\mathrm{Al}$ igual que en Colombia y Argentina, en muchos países de la región, los médicos abanderados del proyecto higienista validaron su poder para representar a la sociedad en su conjunto con base en la efectividad atribuida a las disciplinas científicas y en su condición de varones letrados. De acuerdo con las corrientes del positivismo, el darwinismo social y la antropología forense, difundieron la visión de la degeneración adjudicada a las clases peligrosas y legitimaron su proyecto de limpieza social. En la categoría "clases peligrosas" incluyeron a tuberculosos, sifilíticos, alcohó- 
licos, prostitutas, vagos, mendigos, criminales, sediciosos, entre otros, pero también a los grupos racializados (Facundo 2006). La virtud sexual de estos grupos era motivo de desconfianza y se pensaba que su grado de moralidad no era lo suficientemente alto para poder asimilar las libertades que traía la modernidad. En este sentido, el origen indígena o africano de buena parte del pueblo latinoamericano fue percibido por sus clases dirigentes como un impedimento para el desarrollo nacional.

En Colombia por ejemplo, la representación de las clases populares bogotanas se vinculó a la figura de un indio maloliente, analfabeto, amenazado por la sífilis y poseído por el chichismo, enfermedad ocasionada por el abuso de la chicha, una bebida alcohólica producida con base en la fermentación del maíz. Y las chicherías fueron uno de los espacios más combatidos desde el periodo colonial, ya que alrededor de ellas se tejió todo una serie de estereotipos sexistas y racistas que afectó a las mujeres indígenas que eran sus propietarias o administradoras. En estos locales se subvirtieron los valores morales más arraigados en la sociedad de la época, dando cabida a encuentros erótico afectivos interraciales e interclase, sin vínculos matrimoniales y promoviendo la independencia económica femenina (Rodriguez) .

Vale la pena señalar que muchos lugares de socialización popular como tiendas, chicherías y campos de tejo, hacían parte del mismo lugar de habitación, incluyendo en ellos a las mujeres. Sin embargo, la separación de los espacios de socialización de los de habitación que propuso e impuso la industrialización (de la mano del higienismo) trajo consigo la segregación sexual del espacio y la reclusión de las mujeres el espacio privado. Con la difusión de la idea de que sólo las prostitutas frecuentaban estos lugares, la mayoría de las mujeres perdió la posibilidad de visitarlos, por lo menos de manera abierta y las mujeres de sectores populares y racializados que continuaron haciéndolo quedaron estigmatizadas sexualmente (Facundo 2006).

Para el higienismo, toda conducta femenina desviada de las buenas costumbres y rectitud moral podía tener repercusiones negativas en la sa- 
lud de una población en edad productiva. Así, la condena y persecución de quienes se dedicaban a la prostitución fue un elemento clave dentro de las políticas de la higiene social liberal. No solo había motivos de índole moral y de ordenamiento social, sino de la protección de la salud de las posibles víctimas de las enfermedades venéreas que incluyeron muchas veces a los miembros de los grupos dirigentes. Todo esto provocó el desarrollo de una estrategia médica dirigida desde el Estado, que buscó ejercer un control estricto de todas las prostitutas. Sin embargo, tal expectativa no pudo cumplirse, dado que gran porcentaje ejerció tal actividad sin estar debidamente registradas. El trabajo de Sueann Caulfield sobre la regulación de la prostitución en Rio de Janeiro a finales del siglo XIX y comienzos del siglo XX es un buen exponente de las contradicciones en que se debatía un país como Brasil en un momento en que pugnaba por mostrarse ante el mundo como una nación moderna. Como tal, debía exhibir una postura "abolicionista" o antirreguladora en relación con la prostitución; sin embargo en la práctica siempre se movía hacia el reglamentarismo y la utilización de represión policial.

Caulfield examina la historia de la gradual transformación de Mangue, un barrio situado lejos del centro de la ciudad, en un distrito de mala reputación regulado por la policía y objeto de intervenciones de saneamiento. Esta evolución es puesta en relación con las dos caras contrastantes de la prostitución carioca: la que ejercían con cierto refinamiento las francesas y las mulatas brasileras, toleradas, admiradas y protegidas por algunos hombres de las clases privilegiadas. Estas se ubicaban en Lapa, llamado el Montmartre tropical. Su contraparte era la prostitución que se ejercía en Mangue, escogido por la policía como depósito de las prostitutas "escandalosas”, las pretas y las europeas de clase popular, llamadas las polacas. El trabajo de Caulfield analiza igualmente los conflictos de poder entre profesionales, legisladores y oficiales de policía en torno a unas disposiciones reguladoras de la prostitución que pusieron de presente de forma muy explícita "los prejuicios raciales, étnicos y de clase que componían el ideal nacional de las elites brasileras" (Caulfield I998: I40). Los debates 
teóricos que suscitaron la prostitución y su regulación en este período muestran las distintas formas en que la raza, la etnicidad y la clase social se entrecruzaron con la sexualidad para crear las normas conyugales y familiares y las imágenes de nación que se buscaba construir.

En las distintas estrategias que buscaban apuntalar el orden nacional republicano, el dispositivo del honor continuó desempeñando un papel importante, pero con un nuevo significado. Ya no fue pensado, como en el período colonial, como una característica "natural" propia de las elites blancas, sino como una aspiración, ampliamente compartida, de adquirir la respetabilidad a través de la educación, la ocupación, la capacidad de entrega al trabajo y la adopción de una conducta moderada y virtuosa. Estos atributos fueron centrales en la formación de una cultura política republicana distintiva forjada en torno al respeto de la dignidad y de los derechos civiles de los hombres trabajadores del común. El cumplimiento de sus responsabilidades públicas los autorizó a ejercer en privado su autoridad patriarcal a través del control de la sexualidad de las mujeres, en el marco de una masculinidad vigorosa pero civilizada. Así, se selló un pacto patriarcal interclasista que permitió aunar esfuerzos en aras de construir una nación moderna y tolerante racialmente, fundada en los valores familiares tradicionales (Wade 2009).

Sin embargo, este mismo proyecto estaba plagado de contradicciones: mientras buscaba una mayor fluidez en las relaciones raciales pretendía ejercer un férreo control de la laxitud moral que se atribuía a los grupos racializados, mediante políticas y programas de intervención social. Y al mismo tiempo que promovía los valores de la modernidad salvaguardaba de ellos a las mujeres. Los grupos racializados, al igual que las mujeres, compartían el mismo estatus social minorizado y suscitaban las mismas sospechas, por ser considerados incompetentes para adecuarse a los mandatos de la modernidad. Así los únicos que pudieron beneficiarse totalmente de la modernidad fueron los hombres blancos heterosexuales de las clases superiores que monopolizaban las reglas del control moral y el privilegio de la honorabilidad. 
A lo largo del siglo XX se elaboraron distintas estrategias para consolidar proyectos nacionales que permitieran definir la región como una extensión de los ideales liberales y democráticos de la modernidad. En este proyecto se entretejieron medidas de regulación de las prácticas cotidianas a través del dispositivo del honor, políticas nacionales de salud pública y programas de higiene social que buscaban con determinación liberar al pueblo de la mácula de su «barbarie» original. En Brasil se hicieron múltiples tentativas para integrar a los pretos y pardos en una sociedad de clases y hacerlos encajar en la imagen de la nueva nación democrática en términos raciales (Freyre 2006 [1933]). En Ecuador también se intentó transformar las periferias de la nación habitadas por los ecuatorianos racializados mediante proyectos de desarrollo que permitieran adecuar tanto a las tierras como a su gente a la ideología del progreso y la modernidad y a los modelos de modernización y crecimiento industrial (Whitten I98I). En México, el mestizaje fue pensado como una fusión de razas que debería apuntar al blanqueamiento del país pero desafiando la superioridad europea (Aguirre Beltrán 1969). Este planteamiento fue aplicado durante todo el siglo XX como un discurso estatal suficientemente flexible pero firme en su deseo de generar una identidad mexicana desracializada y nacionalizada, apta para su pleno acceso a la modernidad. Solo a finales del siglo XX, los movimientos indígenas y negros lograron cuestionar el modelo de la nación mestiza y hacer reconocer la multiculturalidad de las sociedades latinoamericanas. Ahora bien, ¿qué trajo al repertorio de valores sexuales y de género el giro multicultural?

\section{A modo de conclusión: las paradojas del multiculturalismo neoliberal}

Desde la adopción de su nueva constitución en 199I, Colombia, al igual que otras naciones latinoamericanasfue redefinida como una nación “pluriétnica y multicultural”. A través de estas nuevas constituciones muchos países de la región buscaron resolver la ambigüedad que producía 
reconocerse y desconocerse al mismo tiempo en relación con sus orígenes americanos, europeos y africanos. Sin embargo, este reconocimiento de la multiculturalidad no significó abolir totalmente las categorías raciales en las interacciones cotidianas sino reemplazarlas gradualmente por denominaciones que hacían referencia a la etnicidad y la cultura para legitimar y normalizar las prácticas modernas del racismo, (De la Cadena 2000). En este nuevo contexto se generó una configuración social particular en la cual, como señala Peter Wade, coexisten racismo y democracia racial, en tanto fenómenos no únicamente sincrónicos sino interdependientes. (Wade 2009: 158).

Por otra parte, la respuesta a las demandas de los movimientos indígenas y de afrodescendientes ha sido muy limitada, si se la compara con la extensión de las reformas neoliberales que se han dado en el mismo periodo. Tal como lo señala Charles Hale (2004), existe una correlación entre "los gobiernos que han desarrollado las políticas más extensas de derechos indígenas y reconocimiento cultural en Latinoamérica” y los que "han promovido las reformas económicas neoliberales". Hale argumenta que como resultado de esta combinación, se ha generado una nueva forma de gobernar a los ciudadanos que él llama "el proyecto cultural del neoliberalismo" que consiste en la apertura de espacios de participación para los grupos étnicos mientras al mismo tiempo se crean límites que abortan sus aspiraciones más transformadoras”. Desde distintas perspectivas, diferentes autores (Gros 1997, Hale 2005, Wade 20I0, Viveros 20I2) coinciden en señalar que el multiculturalismo en vigor no solo no ha logrado reducir los efectos racializados de las políticas neoliberales que afectan especialmente a estos grupos étnicos sino que ha contribuido a reproducir su marginalidad social.

Si bien hay que matizar esta afirmación teniendo en cuenta las experiencias de los distintos países en términos de reconocimiento de derechos étnicos y culturales vale la pena retener la contradicción que recalca Hale al decir que el multiculturalismo neoliberal ha logrado el reconocimiento de derechos culturales, pero no el reconocimiento de las desigualdades so- 
ciales. La paradoja radica entonces en que el multiculturalismo neoliberal refuerza el racismo contra el que supuestamente lucha. A manera de ejemplo de estas contradicciones voy a referirme para terminar al caso de las clases medias negras en Colombia, que he estudiado en los últimos años. La realidad del surgimiento de una clase media negra podría ser a primera vista el efecto de la democratización de las relaciones raciales que trajo el multiculturalismo, sin embargo un análisis más detallado no permite sostenerlo. Si bien las políticas multiculturales abrieron un espacio político para las comunidades negras y para el surgimiento de una identidad étnica menos difusa que la que existía anteriormentela existencia de este pequeño grupo social ha sido fundamentalmente el resultado de su inserción en el mercado capitalista y de su constitución simbólica como un nuevo grupo de poder por parte de los medios masivos de comunicación.

En relación con el racismo, los resultados de nuestras investigaciones señalan que a pesar de que esta pequeña capa de la población negra tiene acceso al consumo de las clases medias bogotanas, en muchas oportunidades se ve obligada exhibir los códigos adecuados de clase, género y sexualidad para no sufrir las consecuencias de ser percibidos como "negras o negros”, en una sociedad que sigue haciendo equivalente pobreza, y negridad (Gil 20IO). Este comportamiento juega como un elemento protector que les permite escapar a discriminaciones raciales potencialmente más severas para la gente de piel más oscura o incluso para las personas de piel más clara que no logran encarnar adecuadamente las normas de clase y de género que están asociados a los sectores medios y superiores de la capital.

En el contexto del multiculturalismo las mujeres y hombres negros que buscan un ascenso social han de acoger los valores y comportamientos que los vuelven respetables y los alejan de los estereotipos negativos que siguen pesando sobre ellas y ellos. Las mujeres deben ser sobrias y discretas en su tono de voz, gestualidad y comportamiento social, y adecuar su presentación personal a la imagen estética de la feminidad valorada en estas clases sociales. Deben desexualizarse después de cierta edad y de haber adquirido el estatus de casadas, previniendo posibles equívocos de la vida cotidiana y 
laboral que evoquen su supuesta lubricidad "natural", uno de los prejuicios raciales más persistentes sobre la sexualidad de las mujeres negras (Viveros 2004). Por su parte, los hombres deben ser trabajadores responsables, buenos proveedores económicos y ojalá los únicos o los principales; deben moderar la expresión del gusto por los comportamientos licenciosos y tener modales de caballeros en el espacio público, para disociarse de la vulgaridad y desenfreno que se imputan a los hombres negros de sectores populares (Viveros 2002). Y no solo deben adoptar y encarnar estas normas de género, sino también las normas sexuales que señalan que las mujeres y los hombres "normales" deben ser heterosexuales y renunciar a cualquier comportamiento que ponga en duda su virilidad o feminidad. Únicamente de esta manera pueden pretender beneficiarse de los réditos sociales de la respetabilidad.

Sin embargo, las mujeres y hombres negros que desean ascender socialmente ya no pueden contentarse con asumir los valores que corresponder al ethos moderno del periodo republicano, en que la capacidad de trabajo, la conducta moderada y virtuosa, la racionalidad productiva y búsqueda de un beneficio estable y continuo les aseguraba su inserción en la Sociedad mayor. El multiculturalismo neoliberal que reconoce sus diferencias culturales, si desean afirmarlas, los acoge de forma condicional. Ellas y ellas tienen claro que este ascenso solo se va a lograr con base en su esfuerzo individual y en su capacidad de autogestionarse. Igualmente saben que están obligadas a repetir constantemente el guion social de la "blanquidad" - en el que representan un papel muy importante las normas de género y sexualidad que son a la vez, como lo señalamos anteriormente, normas de clase — , para que este estatus al que acceden tenga cierto efecto de permanencia. El éxito alcanzado por algunos solo puede sugerirle a los demás que "el camino más factible para avanzar socialmente no es la movilización colectiva, sino la perseverancia y el esfuerzo individual" (Andrews 2007:318).

En conclusión, las sociedades latinoamericanas multiculturales de hoy no son más democráticas en términos raciales que las naciones fraguadas 
por las ideologías del mestizaje ni le asignan menor importancia a la raza. Por otra parte, el neoliberalismo - como ideología del capitalismo global —, pese a su apariencia y discursividad aparentemente "neutrales", prolongó las lógicas económicas de la modernidad temprana que privilegiaban, desde una perspectiva sexista y racista, los atributos que se asociaban a un empresario "blanco", física o políticamente, sin hacer visible su lugar de privilegio (Frankemberg 2004). Las transformaciones que trajo el giro multicultural tampoco aportaron una redefinición del repertorio cultural sexuado y racializado preexistente, sino su adecuación a las nuevas estrategias de mercado y prácticas de consumo (Castells i998). Así, el mandato del blanqueamiento social en la era del multiculturalismo neoliberal ha seguido cumpliendo eficazmente su función, incluyendo a unos pocos, fortaleciendo la ideología de la meritocracia anclada en el individuo, constituyendo subjetividades que internalizan sus normas y valores sexuales y de género y difundiendo representaciones racializadas del mundo que inciden hasta en los dominios más íntimos de la vida social.

\section{Referencias bibliograficas}

AGUIRRE BELTRÁN, Gonzalo. (1969) "Oposición de raza y cultura en el pensamiento antropológico mexicano”. Revista Mexicana de Sociología, Vol. 3 I, No. I (Jan. - Mar.) pp. 5I-7I. Universidad Nacional Autónoma de México

ANDREWS, George Reid (2007). América Afro-Latina (I800-2000). Trad. Magda Lopes. São Carlos, SP: EDUFSCAR.

CASTELLS, M. (1998): "Paraísos comunales: identidad y sentido en la sociedad red", en La era de la información. Economía, sociedad y cultura. Vol. 2. El poder de la identidad. Madrid, Alianza, pp. 27-90.

CAULFIELD, Sueann (1997). El nacimiento de Mangue: La raza, la nación y la política de la prostitución en Rio de Janeiro, I850-1942, en Daniel Balderston 
y Donna. J. Guy (Comp.), Sexo y sexualidades en América Latina, Buenos Aires: Paidós, pp. 139-162.

DE LA CADENA, Marisol (2000) Indigenous mestizos: the politics of race and culture in Cuzco, 1919-199I (Durham, NC: Duke University Press).

FACUNDO NAVIA, Ángela (2006) Los padres y las madres de la patria. Representaciones médicas de las mujeres en Bogotá a comienzos del siglo veinte, en Mara Viveros, Claudia Rivera y Manuel Rodriguez (comps.) De mujeres, hombres y otras ficciones...: género y sexualidad en América Latina Bogotá: Tercer Mundo : Universidad Nacional de Colombia, Facultad de Ciencias Humanas, pp. 77-96.

FRANKENBERG, Ruth (2004). A miragem de uma branquidade não marcada, em Vron Ware (org.) Branquidade: identidade branca e multiculturalismo. Rio de Janeiro: Garamond, 2004

FREYRE, Gilberto, (2006 [1933]) Casa-Grande e Senzala. Formação da familia brasileira sob o regime da economía patriarcal, Sao Paulo: Global Editora.

GIL, Franklin. (20I0). Vivir en un mundo de blancos. Experiencias, reflexiones y representaciones de 'raza' y clase de personas negras de sectores medios en Bogotá D.C. Tesis para optar por el título de Magíster en Antropología Social. Departamento de Antropología. Universidad Nacional de Colombia.

GROS, Christian. (1997) "Indigenismo y etnicidad: el desafío neoliberal, en Antropología en la modernidad: identidades, etnicidades y movimientos sociales en Colombia. Bogotá: Instituto Colombiano de Antropología, pp. 15-60

GUY, Donna (1991). Sex and danger in Buenos Aires: prostitution, family, and nation in Argentina (Lincoln, NB: University of NebraskaPress).

HALE, Charles. (2005) Neoliberal Multiculturalism: The Remaking of Cultural Rights and racial Dominance in Central America. PoLAR. Political and Legal Antbropology Review, 28 (I): IO-28

HERING, Max (2007). Raza: Variables Históricas. En: Revista de Estudios Sociales 26

LEAL LEÓN, Claudia (2010). “Usos del concepto 'raza' en Colombia”, en Claudia Mosquera Rosero-Labbé, Agustín Laó Montes y César Rodríguez 
Garavito (comp.) Debates sobre ciudadanía y políticas raciales en las Américas negras, Bogotá: Universidad Nacional de Colombia, pp. 389-438.

MORENO FIGUEROA, Mónica. (2OI2) "Yo nunca he tenido La necesidad de nombrarme": reconociendo el racismo y el mestizaje e México", en Alicia Castellanos Guerrero, y Gisela Landázuri Benítez (coord.) Racismos y otras formas de intolerancia de Norte a Sur en América Latina, México: Universidad Autónoma Metropolitana y Juan Pablo Editor, pp. 15-49.

RODRIGUEZ, Pablo (Dir.) (2010) Historia que no cesa: La Independencia de Colombia, I780-I830. Bogotá: Universidad del Rosario.

SILVERBLATT, Irene (1987) Moon, sun, and witches: gender ideologies and class in Inca and colonial Peru (Princeton, NJ: Princeton University Press).

STOLCKE, Verena (1992). Racismo y sexualidad en la Cuba colonial. traducción de Ana Sánchez Torres. Madrid: Alianza [etc.]

VIVEROS VIGOYA, Mara y GIL HERNÁNDEZ, Franklin (2010) Género y generación en las experiencias de ascenso social de personas negras en Bogotá. Maguaré, nº 24, 2010, pp.99-130.

VIVEROS VIGOYA, Mara (2002). De quebradores y cumplidores: sobre hombres, masculinidades y relaciones de género en Colombia. Bogotá, CES, Universidad Nacional de Colombia, Fundación Ford, Profamilia Colombia.

VIVEROS VIGOYA, Mara (2004). El gobierno de la sexualidad juvenil y la gestión de las diferencias. Reflexiones a partir de un estudio de caso colombiano. Revista Colombiana de Antropología, vol. 40, enero-diciembre, pp. 155 -I 83 .

VIVEROS VIGOYA, Mara. (Coord.) (20II). Informe de la investigación Hexca Colombia, Enero 19.

VIVEROS VIGOYA, Mara (20I2). Sexuality and Desire in Racialized Contexts. In: AGGLETON, Peter; BOYCE, Paul; MOORE, Henrietta L; PARKER, Richard. (Ed.) Understanding Global Sexualities. New Frontiers. London, New York: Routledge, pp. 218-23I.

VIVEROS VIGOYA (20I3), Mara. Movilidades y desigualdades espaciales y sociales en el contexto del multiculturalismo latinoamericano. Una lectura en clave de género, en Juliana Ströbele-Gregor y Dörte Wollrad (ed.) Espacios de 
género. Buenos Aires, Nueva Sociedad/Fundación Friedrich Ebert/Adlaf, pp. I89-203.

WADE, Peter (1997). Gente negra, nación mestiza. Dinámicas de las identidades raciales en Colombia. Bogotá, Editorial Universidad de Antioquia/ ICAN / Siglo del Hombre Editores/ Ediciones Uniandes.

WADE, Peter (2008). “Debates contemporáneos sobre raza, etnicidad, género y sexualidad en las ciencias sociales, en Peter Wade, Fernando Urrea Giraldo y Mara Viveros Vigoya (editores), Raza, etnicidad y sexualidades. Ciudadania y multiculturalismo en América Latina, Bogotá: Universidad Nacional de Colombia. Facultad de Ciencias Humanas. Centro de Estudios Sociales (CES), Escuela de Estudios de Género, pp. 4I-67

WADE, Peter (2009). Race and Sexuality in Latin America. London, Pluto Press, 2009 .

WADE, Peter. (2010) “Liberalismo, raza y ciudadanía”, en Claudia Mosquera Rosero-Labbé, Agustín Laó Montes y César Rodríguez Garavito (comp.)

Debates sobre ciudadanía y politicas raciales en las Américas negras, Bogotá: Universidad Nacional de Colombia, pp. 467-489.

WHITTEN, Norman (ed.). (198I). Cultural transformations and etbnicity in modern Ecuador. Urbana: University of Illinois Press. 